\title{
Notas
}

\section{De lo inmediato: la narrativa de Alberto Fuguet}

\author{
Miguel G. Rodríguez Lozano*
}

Resumen:

En este ensayo se destacan algunas de las características de la narrativa del escritor chileno Alberto Fuguet. Se intentan mostrar los rasgos que se relacionan con la propuesta estética y la visión de mundo del autor, desde la sola lectura de las obras. Esto con el fin de ejemplificar uno de los procesos de escritura por los que pasa América Latina desde hace unos diez años, en un ámbito en el que los escritores nacidos en los años sesenta tienen ya una presencia de peso que a veces se distancia de las estéticas del llamado boom o posboom.

En la década de los noventa del siglo pasado, la literatura latinoamericana observó, concretamente en el campo de la narrativa, un auge que visto con cierta distancia no sorprende, más bien se justifica en forma amplia por la interrelación generacional suscitada entre escritores consagrados, los del llamado boom, los que vinieron después de dicho movimiento, hasta los que iniciaron su experiencia creadora, es decir, los nacidos en los años sesenta y setenta, quienes arribaron al mundo de las letras de este continente.

Varias generaciones de autores se congregaban a lo largo de la América Latina de fines de siglo. Se reeditaban obras (las de María Luisa Bombal, por ejemplo); se volvía la mirada a escritores que tenían una obra cuantitativay de calidad (Ricardo Piglia, Luis Britto);

*Profesor-investigador. Universidad Nacional Autónoma de México. 
se destacaba la fuerte presencia del cuento breve con autores como Ana María Shua y se reflexionaba sobre la literatura escrita por mujeres, la cual tuvo un vertiginoso empuje editorial que influyó en el rescate y la revaloración de las obras de Luisa Valenzuela, Cristina Peri Rossi o Ana Lydia Vega, entre muchas otras.

Los lectores nos enfrentábamos a múltiples visiones que igual ponían en jaque la imagen macondiana del continente 0 participaban de la tradición realista o eurocentrista de parte de la narrativa realizada el siglo pasado. Con ello, se auguró el buen estado de la narrativa de finales del siglo en Latinoamérica. En efecto, más allá de las grandes luminarias, canonizadas, Juan Rulfo, Gabriel García Márquez, Juan Carlos O netti o Guillermo Cabrera Infante, el fin del siglo pasado dispuso un abanico de posibilidades, tendencias, visiones de mundo que, por fortuna, siguen extendiendo la experiencia lectora y hacen posible el estudio de esas obras fuera de los márgenes del canon.

Los escritores nacidos en los sesenta y setenta son esa parte de la historia cultural que todavía hoy, en los inicios del siglo XXI, nos da una idea de hacia dónde van los intereses literarios de los autores latinoamericanos. Juan José Rodríguez, Jaime Bayly, Pablo de Santis, Ricardo Chávez Castañeda, David Toscana, Andrea Maturana, Mayra Santos, entre los novelistas, o Eduardo Antonio Parra, entre los cuentistas, todos con su individual propuesta estética, conforman en estos momentos la narrativa latinoamericana actual, viva, llena de sorpresas y, por supuesto, contundentemente aprehensible para su estudio.

Alberto Fuguet (Santiago de Chile, 1964) representa un ejemplo idóneo, como una tendencia no única, de lo que sucede en esa narrativa latinoamericana que se percibe en estos momentos. Hasta ahora, Fuguet ha publicado cuatro novelas: Mala onda (1991), Por favor rebobinar (1994), Tinta Roja (1996) y Las películas de mi vida (2003); dos libros de cuentos, Sobredosis (1990) y C ortos (2004), más el libro de crónicas Primera parte (2000). ${ }^{1}$ Periodista de profesión,

${ }^{1}$ Esto sin contar su trabajo como editor, que ha dado pie a tres antologías de cuento, algunas de ellas en colaboración: C uentos on walk man (1993), M c0 ndo (1996) 
actividad que influirá en su obra completa, Fuguet forma parte de la literatura chilena, en la que encontramos narradores de la talla de José D onoso, Diamela Eltit, Jorge Edwards, Antonio Skármeta, Roberto Bolaño o Isabel Allende.

Desde el libro de cuentos, su primera obra publicada, son notables los intereses estéticos y de contenido que mantiene a lo largo de su producción. Las narraciones destacan sobre todo por el uso de la primera persona y su ubicación en la ciudad de Santiago, que se convierte en el centro espacial por el que deambulan los personajes. El mundo de los jóvenes de clase media y los espacios citadinos marginales; la experiencia de vida vinculada con el mundo de la música, las drogas, los mass media (cine, televisión, radio, periódico), pero sobre todo la presencia del cine - no sólo en cuanto a la mención de películas (el mismo título de su novela, Las películas de mi vida, por ejemplo), sino también en las técnicas cinematográficas que por momentos se presentan en las obras, el estilo road movie de Tinta Roja, o el fanatismo hacia el cine hollywoodense del personaje Lucas en Por favor rebobinar-, conviven en la estética fuguetiana de modo incuestionable, con una solidez en la construcción formal y conceptual que hace posible distinguir ya un estilo preciso en esta narrativa.

Todas las obras se identifican plenamente con el mundo de los jóvenes, con su experiencia de vida. Se trata de ambientar los sentimientos, sensaciones, modos de ser, de pensar y de actuar de la generación nacida en los sesenta, aquella que vivió la cultura poshippie de los años setenta y ochenta; aquella que creció en el desgano del fin de siglo, con el neoliberalismo y la globalización como estandartes de un mundo aparentemente estable, en el que la sociedad teledirigida y la revolución multimedia se convirtieron en un punto clave de los noventa. En varios aspectos, la narrativa de Fuguet participa de ese dejarse ir de personajes como el de la novela $\mathrm{G}$ eneración X de D ouglas Coupland, 0 en el extremo, con la posición violentamente contestataria, a su modo, de A merican Psycho de

y Se habla español (2000). A demás, publicó su cuento y guión de cine: D os hermanos. Tras la ruta de En un lugar de la noche (2000). 
Bret Easton Ellis. La literatura de Fuguet llega a marcar esas sensaciones sociales que retoman mucho de la sociedad norteamericana. De manera evidente, la visión de Fuguet respecto a América Latina, a Chile y la literatura, sí busca ser contestataria, rebelde, sin concesiones; se distancia en forma deliberada de lo institucional. Nótese el tono que impone el autor a la siguiente reflexión polémica:

El arte latinoamericano, en general, y el chileno en particular, poseen la lamentable característica de no ser capaces de salir de lo folclórico, de creerse el cuento insular, de empantanarse en lo contingente y en lo criollo. Han capitalizado el realismo mágico y eso de que América Latina es un continente misterioso [...] Pero hay otra América Latina y, definitivamente, otro Chile que necesita ser escrito, exportado y compartido. Aquellos que se quedan en los huasos, las nanas y los rosarios pueden seguir haciéndolo. Pero quienes no escriban de los nuevos huasos con celular, los de los kiwis y las four wheel drive, de los malls y las discotheques al borde de la Panamericana, se estarán perdiendo un gran material. Porque esto también es Chile. Y no corresponde sólo a un sector social. Chile, al menos por ahora, no es Macondo ni otro invento garciamarquiano. Todo lo contrario: es McCondo, tierra de $\mathrm{McD}$ onald's y condominios, de computadores y autos japoneses [...] Chile es urbano y basta de mentir y seguir escribiendo de vacas. La provincia no está llena de gente que duerme siesta [...] Algunos podrán emocionarse ante esta nueva escenografía en vías de privatización. O tros se sentirán asqueados. Todo vale. Los artistas, en especial los escritores, tienen el deber moral de narrar historias que de alguna manera recojan el país real, no el mítico. (Fuguet, Primera parte 145-46)

Este modo de enfrentar la realidad cotidiana, cultural y literaria a través del discurso ensayístico, será puesta en práctica en los textos de creación. De hecho, ambos tipos de discursos se complementan. Cada uno a su modo radicaliza la visión de mundo propuesta por Fuguet. 
Por consiguiente, esta narrativa es eminentemente urbana; los varios narradores se regodean con la descripción de las diferentes zonas de Santiago, barrios populares o no, y al hacerlo se objetiviza el espacio por medio del lenguaje. Tal acción es explicable si se piensa en el tipo de protagonistas que se vuelven el centro de las acciones y/ o las reflexiones que se desarrollan en las obras. En su mayoría, como se ha señalado, jóvenes que nos hacen partícipes de su mundo cotidiano con un lenguaje ágil y frecuentemente coloquial: "Estoy en la arena, tumbado, raja, pegoteado por la humedad, sin fuerzas siquiera para arrojarme al mar y flotar un rato hasta desaparecer. Estoy aburrido, lateado: hasta pensar me agota. D esde hace una hora, mi única distracción ha sido sentir cómo los rayos del sol me taladran los párpados, agujas de vudú que alguna ex me introduce desde Haití o Jamaica [...]" (Fuguet, Mala 9). O: "Me bajé del metro y las nubes culeadas aún no se largaban a llover. Entré a un café y pedí un cortado. Fui al baño a mear. Me bajé el cierre y frente a mis ojos, en la pared, una letra temblorosa decía: Is There A nybody O ut There? D ebajo, con una letra negra, gruesa, segura, alguien respondía: N 0 . Me sacudí, tiré la cadena y salí. Miré a mi alrededor y, efectivamente, no había nadie" (Fuguet, Sobredosis 132). Este síntoma de desapego se mantiene en varios textos y es muy similar cuando se trata precisamente de personajes jóvenes: "Está claro: soy un extra en mi propia vida. No he tenido dirección, me he confundido con los decorados, mi personaje no aparece siquiera en los créditos [...] Estoy en la punta del Empire State, no funcionan los telescopios y está nublado. ¿Se entiende? Digamos que así me siento. Así estoy" (Fuguet, Por favor 15). Sin embargo, el modo desencantado es una constante que no sólo aparece en los protagonistas jóvenes, sino también en los adultos. En Por favor rebobinar no hay escape posible en la inercia de la vida para uno u otro personaje. El psicólogo Max, quien evade su entorno por medio de la droga, es incapaz de sobrellevar su propia vida y mucho menos la de sus jóvenes pacientes (uno de ellos termina suicidándose); el mismo efecto se dará en Tinta roja, con el veterano periodista de nota roja Saúl Faúndez, quien se regodea con el ligue amoroso de las viudas de los asesinados, mientras cubre la noticia para el periódico 
en el que trabaja. También los personajes femeninos, que son siempre observados por el narrador principal, llevan una vida consecuente con lo que los rodea; se trata de seguir el vaivén de la existencia sin complicaciones.

Esa sensación de hastío, de cierto decadentismo, se encuentra a lo largo de la lectura de las primeras novelas, las cuales, no obstante, tienen finales optimistas. En efecto, en cada novela se narra literal o metafóricamente, el viaje de los protagonistas, con todos los procesos socioculturales, las relaciones interfamiliares, la búsqueda de sí mismos, el rechazo social, etcétera; al final ellos tienen la posibilidad de seguir adelante, aunque sea por un momento. Matías Vicuña, el personaje de Mala onda, reflexiona: "Y mientras más desciendo, mientras más me acerco a mi casa, más fuerte me siento. Es como si el viento me purificara. Es como si tuviera ganas de llegar. De avanzar. D e dejar atrás la mala onda, la duda, enfrentar lo que me espera allí abajo. Sobreviví, concluyo. Me salvé. Por ahora" (335). Y el caso de uno de los personajes de Por favor rebobinar, G onzalo McClure, con quien se cierra la novela: "Se me ocurre que no se trata tanto de armarse un mundo sino saber cómo insertarse en él. Pensar que antes lo único que deseaba era formar una banda. Ahora sólo quiero formar una familia. D ios, cómo nos cambia la vida" (388). El mismo efecto de transformación sucede con Alfonso Fernández, de Tinta Roja, quien al final de la novela se reúne con su hijo, y espera estar a la altura del encuentro que es una oportunidad única. Estos finales acentúan el proceso de la narrativa de Fuguet. Sus protagonistas han ido creciendo; no es de extrañar que Alfonso Fernández, al recordar parte de su vida cuando es joven, lo haga desde su mirada de un hombre de cincuenta y tres años.

Lo anterior evidencia algunos de los recursos usados por el autor y por supuesto la relevancia del lenguaje utilizado, que es coherente con el ámbito y los personajes de las historias. El autor tiene un control sobre su escritura y así lo demuestran las descripciones y diálogos. En Tinta roja, por ejemplo, las escenas de asesinatos violentos, en una ciudad que participa de una aparente tranquilidad, pero que convive con los medios masivos de comunicación, poseen la eficacia precisa para impactar en la lectura y a su vez servir 
como contraste de la noticia que aparecerá en el periódico, escrita con todo el estilo propio de los periódicos amarillistas:

Santiago es una ciudad muy grande para siquiera intentar conocerla. Todos los días - todas las noches- muere alguien. D a lo mismo, la morgue siempre está repleta, los pacos llenan informes: atropellos, suicidios, estocadas, asesinatos, venganzas, violaciones, incendios, lo que sea. La sangre riega los barrios más pobres y se queda pegoteada en las cunetas. Monreros, lanzas, timadores, sicópatas, travestis, de todo hay en esta podrida viña del señor. Todas las noches son iguales $\mathrm{y}$, cada vez que amanece, surge un nuevo día y hay dos o tres páginas en blanco que llenar, ojalá una portada a color, porque la gente pide que le ilustren sus historias, quieren saber qué pasó, de qué se salvaron, quieren satisfacer sus deseos, sus temores, dar gracias a Dios porque eso que leen les ocurrió a otros y no a ellos. (Fuguet, Tinta 125)

En realidad, en toda su obra, Fuguet aprehende de manera admirable los diferentes campos coloquiales, lo cuales resaltan la cuestión de las clases sociales y el interés del autor por trascender una visión idealista de la ciudad de Santiago. Con respecto a los relatos, las descripciones también son vertiginosas y el retrato de la ciudad y la participación de los jóvenes es ciertamente efectiva en cuanto al modo de narrar.

Una literatura como la propuesta por Fuguet, por supuesto que tiende al realismo inmediato, a las referencias directas. No puede ser de otro modo. En las más de trescientas páginas de cada novela se nos presenta la historia más reciente de Chile, de Latinoamérica, en el que el papel de la globalización cultural deambula por las historias. En ese sentido no debe perderse de vista el contexto histórico-social particular, la historia más cercana, de la cual surge la obra y a la que hace referencia de manera directa 0 aludiendo a ella, me refiero al militarismo, con Pinochet a la cabeza. Por momentos, la narrativa de Fuguet tiene una carga política, cuestionadora, notable en algunas de las escenas que se muestran en $\mathrm{M}$ ala onda con la 
presencia del estado autoritario de Pinochet en los años ochenta. Pero más subversivo resulta el universo del periodismo, la corrupción, y el campo gangsteril de las calles de Santiago que llena las páginas de Tinta roja.

Así, la narrativa de Fuguet no está alejada de lo que es el mundo social y cultural de fines de siglo. El autor no lo rehúsa, por el contrario, convive sin complicarse del momento que le ha tocado vivir. Asume una rebeldía frente a lo institucional. Escribe en revistas y periódicos; es crítico de rock y cine. Como periodista, se permite escribir en diferentes medios. Este aspecto explica, en cierto modo, su estilo y su pasión por un lenguaje que llegue más rápidamente a sus posibles lectores. Tiene que ver también con su idea de la literatura; su rechazo hacia el realismo mágico se nota en la práctica escritural, en su obra creativa. Se trata de abarcar el período del fin del militarismo y las transformaciones al interior de la vida cotidiana y urbana de la ciudad de Santiago de Chile, posteriores a la era Pinochet. Fuguet lo logra en sus novelas y crónicas al adentrarnos a los mundos interiores de sus personajes, quienes participan de la cotidianidad. Por supuesto, no existe una mirada paternalista de la sociedad que el autor va dibujando a través de los viajes de sus personajes. Los ricos, los pobres o los clasemedieros igual son absorbidos por el ritmo de la ciudad, comparten un momento en el que sólo sus diferentes perspectivas ante la vivencia los hace diferentes.

Si podemos considerar la narrativa de Fuguet en su totalidad es cierto que cada título ha marcado su territorio estético, su planteamiento conceptual. Cada obra desde su particular mirada es la evidencia de un interés artístico preciso. El autor ha buscado trascender en la arquitectura de su obra. En Por favor rebobinar por medio de múltiples voces, cada una narrando desde la primera persona, y con estilos de escritura diferentes; en Tinta roja, con la construcción de una historia dentro de otra, logrando con ello un enorme regreso al pasado que resalta el presente ambiguo de los personajes; en L as películas de mi vida con un acertado paralelismo entre las películas mencionadas y la vida del protagonista. En este sentido, la primera novela, $\mathrm{M}$ ala onda, es conservadora en la cuestión formal, ya que es una historia que inicia un tres de septiembre de 1980 y termina el 
día dieciocho. No obstante, su trascendencia radica en el momento social al que alude, es decir, las votaciones de ese año en Chile, que aprobaron una Constitución que confirmó el mantenimiento de Pinochet en el poder hasta 1990.

En suma, cada obra tiene sus propias cualidades intrínsecas que auxilian a comprender mejor el mundo fuguetiano. Más aún, habrá que considerar también para ello la columna periodística que Fuguet publicó durante un año con el seudónimo de Enrique Alekán, en alusión al célebre fotógrafo francés Henri Alekan, columna que contribuye a entender el modo de concebir la práctica escritural, en este caso en la línea del periodismo, la que no se aleja de las prioridades del autor. L a azarosa y sobreex puesta vida de E nrique A lekán que se encuentra en Primera parte, el libro de crónicas, es una obra clave que nos auxilia para obtener una visión casi total del universo creado por Alberto Fuguet.

Con las breves consideraciones generales expuestas en este escrito, se hace evidente, a través de un ejemplo, la presencia de otros autores latinoamericanos, el eje de visión de una de las diversas manifestaciones, que nos indica que debemos empezar a meditar sobre el espacio narrativo latinoamericano desarrollado en el fin del siglo pasado, con la idea de ir más allá de esa crítica literaria que no participa de los recientes modos de creatividad literaria, y que se regodea en la recanonización de los autores ya de por sí consagrados.

\section{Bibliografía}

Fuguet, Alberto. Cortos. Santiago de Chile: Alfaguara, 2004. , ed. Cuentos on walk man. Santiago de Chile: Planeta, 1993. . D os hermanos. Tras la ruta de En un lugar de la noche. Santiago de Chile: Aguialr, 2000.

. Por favor rebobinar. $2^{\mathrm{a}}$ ed. Santiago de Chile: Alfaguara, 1999. . Mala onda. 2a ed. Santiago de Chile: Alfaguara, 1999. y Sergio Gómez, eds. M o0 ndo. Barcelona: Mondadori, 1996. . L as pelíalas de mi vida. Santiago de Chile: Alfaguara, 2003. . Primera parte. Santiago de Chile: Aguilar, 2000. 
. Sobredosis. 8aㅡ. ed. Santiago de Chile: Alfaguara, 1999. . Tinta roja. 3a ed. Santiago de Chile: Alfaguara, 1997.

Paz Soldán, Edmundo y Alberto Fuguet. Se habla español. V oces latinas en USA. México: Alfaguara, 2000. 